\title{
Development and ImPlementation of a Cross Discipline CaPSTONe Design EXPERIENCE AT THE UNIVERSITY OF MANITOBA
}

\author{
W.C.D. DeGagne* and Paul Labossiere, \\ Faculty of Engineering, University of Manitoba, Winnipeg. MB, Canada R3T 5 V6 \\ *William.degagne@umanitoba.ca
}

\begin{abstract}
One of the most effective and efficient ways for an engineering program to facilitate compliance with the Canadian Engineering Accreditation Board (CEAB) accreditation criteria is through capstone design projects and courses. Currently, the University of Manitoba Faculty of Engineering has several capstone design courses; however, each is independently focused on its own respective discipline. The resulting educational experience for students, though rigorous and challenging, is maintained within the boundaries of the students' engineering discipline, thereby neglecting to provide the opportunity for students to work with people from multiple disciplines and across multiple fields. This style/mode of education, where students work in silos, arguably does not reflect real world engineering. Program representatives from the Faculty of Engineering agree. An interdisciplinary capstone course would provide a more rounded engineering education for students. Exposing students to other disciplines and facilitating their learning of the knowledge, skills and behaviours required to work in a multidisciplinary capacity will more effectively prepare students for the real world. Thus, to better comply with CEAB requirements and to increase the breadth and depth of students' engineering education, an interdisciplinary capstone pilot course will be launched at the University of Manitoba.
\end{abstract}

This paper explains how this multidisciplinary capstone pilot program has been developed, and touches on the early stages of its initiation and implementation.

Keywords: Interdisciplinary; multidisciplinary; capstone course; pilot program

\section{INTRODUCTION}

To survive in today's globally competitive and turbulent world, universities have to prepare students to be critical and creative thinkers and problem solvers, skilful communicators and committed team players, who can adapt their skills, and knowledge to work professionally with a diversity of people across multiple disciplines in a variety of settings. Students must be able to leverage their knowledge, skills and behaviours to work successfully in these varied and demanding situations while retaining competitive advantage. As engineering educators, we have a responsibility to prepare our students for these challenges. This requires providing our students with experiences that reflect or model what exists outside of the engineering classroom and in the real world. Additionally, "To prepare engineering graduates it is necessary to articulate the difference between educational problems and workplace problems" [1].

One effective way to prepare engineering students for the global challenges and stringent competition that they will face, is to provide them with authentic, real-world problems to solve. The most comprehensive approach to creating this reality in engineering is through interdisciplinary or multidisciplinary capstone courses. Borrego and Newswander define an interdisciplinary approach as one that "...can be defined when persons from different disciplines work collaboratively and are integrated to combine their knowledge to solve a problem"[2]. Creating an opportunity for students to participate in an interdisciplinary or multidisciplinary capstone course will better prepare them for competitive globalization.

\section{BACKGROUND}

For this paper, a capstone course is defined as "...a project-based learning experience that involves engineering practice through a significant design project whereby student teams meet specific client needs through a creative, iterative, and open-ended design process" [3]. Currently, the University Of Manitoba Faculty of Engineering capstone courses are uni-disciplinary: they are offered through the Mechanical, Civil, Electrical and Computer, and Biosystems Engineering programs. Each is independently designed specifically for its respective discipline, and has unique criteria, performance measurements, time-lines, team formations and credit hours. Similarly though, each is offered in the final year of the program and is intended to facilitate students' synthesis of the knowledge and skills that they have learned throughout their programs, demonstrating the required outcomes for an engineering student prior to graduation. 
The Canadian Engineering Accreditation Board (CEAB) delineates the outcomes required for engineering students graduating from accredited programs. The purpose of the CEAB is to determine those engineering programs whose graduates are academically qualified to begin the process to be licenced as professional engineers in Canada. The process of accreditation emphasizes the quality of the students, the academic and support staff, the curriculum, and the educational facilities. The main goal of the CEAB is to insure that the engineering programs offered by Canadian higher education institutions will meet or exceed minimum educational standards acceptable for professional engineering licensure in Canada.

Recently, the CEAB revised its accreditation procedure to include an outcomes-based assessment of graduating students. The outcomes are characterized by twelve attributes: (1) a knowledge base for engineering; (2) problem analysis; (3) investigation; (4) design; (5) use of engineering tools; (6) individual and team work; (7) communication skills; (8) professionalism; (9) impact of engineering on society and the environment; (10) ethics and equity; (11) economics and project management, and; (12) lifelong learning. Each outcome has a specific definition demarcated by the CEAB. Of interest in this research is the definition for Individual and teamwork: An ability to work effectively as a member and leader in teams, preferably in a multidisciplinary setting [4].

Recognizing that the capstone model currently used in the faculty was perhaps not taking advantage of fostering all of the $\mathrm{CEAB}$ outcomes required of engineering students, particularly the aspect of working within a multidisciplinary setting, as well as recognizing that the present capstone designs in the faculty were not necessary fully emulating 'workplace problems' [1] due to their uni-disciplinary approach, there was a call to action within the faculty. As a result, internal focus group meetings were conducted with faculty program representatives. It was during these meetings that a gap was acknowledged between the existing uni-disciplinary capstone courses and the models for multidisciplinary capstone courses.

Also it must be noted that the Cambridge Handbook of Engineering Education and Research, a renowned publication in engineering education, forecasts two major developments in the next decade: (1) major national or regional efforts to better integrate engineering education research into engineering programs, and (2) increased collaboration (and occasionally tensions) among the growing global communities of engineering education researchers as the field continues to mature, [1]. In other words, the need and demand for practical capstone courses and projects will increase to accommodate accelerated global training.
In this paper we will discuss how the gap in our capstone offering will be filled. We will describe the individual faculty capstones offered by our five engineering programs at the University of Manitoba. We will present our research of recent Canadian Engineering Education Association (CEEA) conference publications and on Canadian institutions, and how institutions across Canada are approaching their capstone challenges. We will discuss the findings from our focus group discussions with our engineering program representatives, which have led to the identification of a key framework for the development of a multidisciplinary capstone pilot course for the Faculty of Engineering at the University of Manitoba. Lastly, we will explain how this multidisciplinary capstone pilot course is being conceived and implemented through a pilot program.

\section{METHODOLOGY}

The research was conducted using the following activities: desk-top modeling; attendance at the CEEA 2015 conference; review of the CEEA papers, and; focus group discussions and decisions.

\subsection{UNIVERSITY OF MANITOBA ENGINEERING CAPSTONE PROGRAMS AND COURSES}

An analysis of the University of Manitoba Faculty of Engineering program capstone courses was conducted. The methods used for this analysis included internet searches, individual discussions with discipline faculty members, and, confirmation of research findings from the discipline representatives. The observations gathered are noted in the Findings section.

\subsection{INTERDISCIPLINARY CAPSTONE COURSES IN CANADA}

In order to develop a multidisciplinary capstone pilot course for the Faculty of Engineering at the University of Manitoba, several steps were taken to explore the state of interdisciplinary and multidisciplinary capstone courses in Canada. The authors attended the 2015 CEEA Conference at McMaster University and reviewed publications from the 2014 and 2015 CEEA annual conferences that focused on interdisciplinary and multidisciplinary capstone courses. Library and Internet searches were performed for interdisciplinary and multidisciplinary capstone courses offered in other Canadian universities. It was noted that several 
universities have either multidisciplinary capstone courses or are developing them at this time.

\section{FINDINGS}

\subsection{UNIVERSITY OF MANITOBA ENGINEERING CAPSTONE PROGRAMS AND COURSES}

Common to University of Manitoba capstones, the following observations were noted: All courses stress team building, team management, project management, and the staged and phased development of deliverable aspects of the CEAB requirements. All capstone courses are given in the final year of the program. Credit hours for the course range from five to eight. All programs recognize the importance of networking with industry and have industry advisors for capstone teams. Each discipline offers their own 'real life' experience to allow teams to be creative and innovative. See Appendix 1, Current University of Manitoba Capstone Course Contrast and Comparison, which describes the courses, and emphasizes their unique qualities. The combined projected total capstone enrolment is about 330 students, and the capstone courses are well managed by faculty and industry advisors to realise the maximum student support.

\subsection{INTER \& MULTIDISCIPLINARY CAPSTONE COURSES IN CANADA}

The research is shown in Appendix 2, CEEA Conference Capstone Papers Contrast and Comparison. The following observations were noted: learning objectives should be tied to outcomes, the CEAB Attributes, and students' reflective learning submissions; the Centre for Engineering Professional Practice and Engineering Education at the University of Manitoba should consider creating a capstone development handbook for future reference as a lessons learned outcome; the capstone project characteristics of scalability, and rapid prototyping to facilitate experiential learning should be encouraged; individual student performance should be tracked in an on-line program; creativity and innovation should be emphasized in prerequisite courses, as well as in the capstone course itself; community-based projects should be included as part of the capstone as a response to social and environmental needs; the flipped classroom model should be applied to increase students real life experiences and personal satisfaction; individual and team face-to-face feedback should be encouraged to enhance the real life experience.

Further library and Internet searches were carried out to expand on the CEEA publication data. It was discovered that the CEEA publications reflect what is happening nationally. The CEEA publications and library and Internet search was combined to form the Canadian national reference. Appendix 2 displays these findings.

\subsection{FOCUS GROUPS}

After the research was completed, the proposed structure of the University of Manitoba Faculty of Engineering interdisciplinary capstone was developed through two focus groups. The first is an internal group consisting of representatives from the engineering disciplines. And the second was made up of an industrial team which is developing and implementing a Winnipeg condominium project. Both focus groups meetings are run formally, with agendas presented and followed and minutes transcribed and distributed to the appropriate stakeholders.

The first group is considered the internal focus group, and has representation from each of the four departments in the Faculty of Engineering: Biosystems, Civil, Electrical and Computer, and Mechanical. This focus group has met three (3) times to develop the internal course details. These in-house meetings establish agreement and commitment within the University of Manitoba Engineering departments on the development of a multidisciplinary pilot capstone course in the Faculty of Engineering. The outcomes of this focus group meetings are shown in Appendix 3, Focus Group Development Schedule.

The second focus group is external to the University of Manitoba. It is the condominium project development team, and is comprised of the architect; structural, mechanical and electrical sub-consultants; the developer and the builder; and the University of Manitoba Cooperative Education representative. The external meetings with representatives from industry garner input on the development of this multidisciplinary pilot capstone course, and to procure industry commitment for providing an authentic project for students in the course. This External group has met four (4) times to formulate and develop all industrial components of the pilot course. The outcomes of this focus group meetings are also shown in Appendix 3, Focus Group Development Schedule.

Some of the key outcomes that came about as a result of the focus group discussions include the following: applying the charrette learning approach; presenting the 
final project at a BOMA meeting, and having the External Team adjudicate a portion of the final grade.

Based on the focus group discussions and the research, the following parameters will be established for the proposed multidisciplinary pilot course: The course will be implemented and managed through the University of Manitoba's Centre for Engineering Professional Practice and Engineering Education (The Centre).

The Mission Statement for The Centre is:

- To ensure that graduating students, both at the undergraduate and graduate levels, have not only the academic knowledge but also the professional skills to pursue careers in the Profession of Engineering.

- To provide a support system whereby academics can both improve their skills as engineering educators and further the scholarship of engineering education and engineering practice.

Since parts of the mission of The Centre is to promote outside interaction and engineering design, and provide a home for researchers interested in the pedagogy of engineering education, it is a natural focus to oversee the interdisciplinary capstone development and implementation.

Further to the discussion groups agreements, the prototype course will be offered in the final year of a four year Engineering program for four credit hours and the structure expanded over the years to reflect new development in the external environment that would make the course more meaningful. Project team members should be from different engineering disciplines and possibly from different faculties. Enrollment in the course will be restricted to students from the five (5) University of Manitoba engineering discipline. It is anticipated that the target class will be eight (8) to twelve (12) students, consisting of three (3) students from each discipline. There will be a strong affiliation with industry or community service. Student performance evaluations will be based on deliverables with a mechanism for internal team peer assessment; and the final submission will consist of an industrial design report including a design prototype. Since the condominium development is an actual project with real constraints and conditions, it will satisfy the target attributes of the CEAB.

\section{NEXT STEPS}

It was determined through the focus groups and research that this initiative will be a technical elective offered as pilot course on a voluntary basis between the Mechanical and Electrical programs at the University of Manitoba. These two disciplines were chosen to launch the initiative because they have worked together closely before and are critical components of project design and construction. It will then be expanded to include the other disciplines after performance qualitative and quantitative evaluations are completed. The course is being advertised and will be launched in January 2017. As stated in the Findings, eight (8) to twelve (12) students are targeted to register for the initial offering. Based on existing course schedules the interdisciplinary capstone will be scheduled as a late afternoon class to respect students' established timetables and the existing course offering formats. It will consist of two hours of lectures and three hours of tutorials per week for site visits and meetings with the external group.

The Internal Group will provide theoretical instruction on how the project is developed. To insure integration of the learning, the Interdisciplinary teams will present design lectures to their fellow classmates. This Charrette process will be used where students will research each discipline design and present it, in a seminar format, to the class as a lecture. The External Group will provide the practical application of the design sharing all the project documentation with the class.

The course structure will comprise a five-part deliverable evaluation including the following stages: review of project criteria; submission of design questions; responses to design questions; project scope change; design to accommodate the scope change. The external group has named a condominium project as the project that will be developed through the course. See Appendix 4, 62M Multi-Family Condominium. The internal group representatives have committed to providing design advisory instruction for the upcoming winter 2017 course.

At this time it is anticipated that the external group will have between 10 and 15 hours contact time with the students over the winter session. To facilitate the external group's tight time frames, meetings with the class will be conducted at the architect's office. At the final stage of course, the internal disciplines will present their designs to the external team for adjudication.

\section{CONCLUSIONS}

This paper has focused on how a multidisciplinary pilot capstone course has been proposed for the Faculty of Engineering at the University of Manitoba in order to create a more meaningful capstone design experience for undergraduate students, better prepare them for professional employment, and enhance compliance with the CEAB Graduate Attributes requirements. 
From the development of this conference paper, I have learned the following important lessons:

- Research and review of publications requires a strong focus to include only salient points

- It is essential to seek out mentoring from someone who has developed conference papers before to assist with the process

- To stay on task, I need to create and follow a rigid outline to stay focused on the big picture

- I look forward to launching the capstone and nurturing it along the way to create a meaningful and practical course that students will benefit from taking.

\section{Acknowledgements}

The authors would like to thank the following individuals:

Douglas Ruth, P. Eng., Ph.D.

Jillian Seniuk Cicek, Ph.D. Candidate

The Internal Interdisciplinary Team, including: Dr. Kristopher Dick; Dr. Dimos Polyzois; Dr. Athula Rajapakse, and; Dr. Robert Derksen

External Industry Team including: Carolyn Geddert; P. Eng., Ted Geddert; Sasa Radulovic; Mark Penner, and; Julien Lavergne

\section{References}

[1] Aditya Johri, and Barbara M. Olds, The Cambridge Handbook of Engineering Education. New York, NY: Cambridge University Press, 2014, pp. \{ISBN:

[2] Maura Borrego and Lynita K. Newswander, "Characteristics of successful cross-discipline engineering education collaborations, "Journal of Engineering Education, vol. 97, no. 2, pp. 123-134, 2008.

[3] $\mathrm{U}$ of $\mathrm{T}$ definition for capstone https://www.mie.utoronto.ca/undergrad/capstone downloaded May 2,2016

[4] Engineers Canada (2012), Canadian Accreditation Engineering Board Accreditation Criteria and Procedures

\section{APPENDIX 1: CURRENT UNIVERSITY OF MANITOBA CAPSTONE COURSE CONTRAST AND COMPARISON}

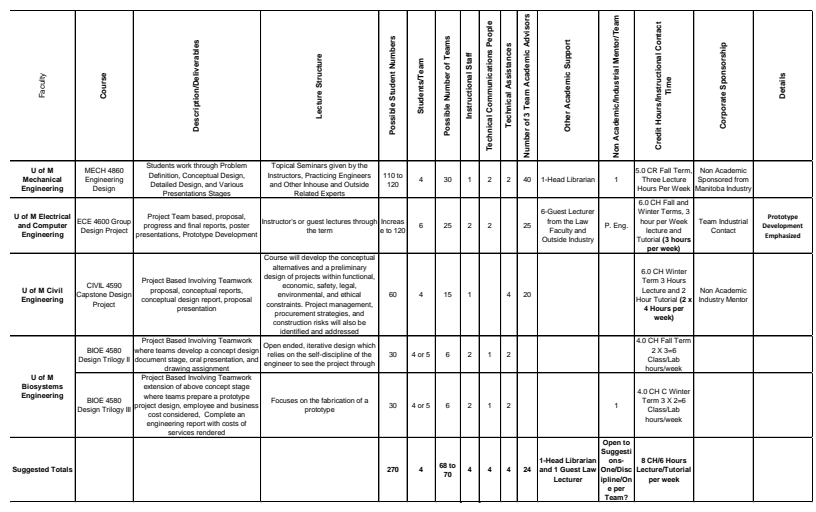

\section{APPENDIX 2: CEEA CONFERENCE CAPSTONE PAPERS CONTRAST AND COMPARISON}

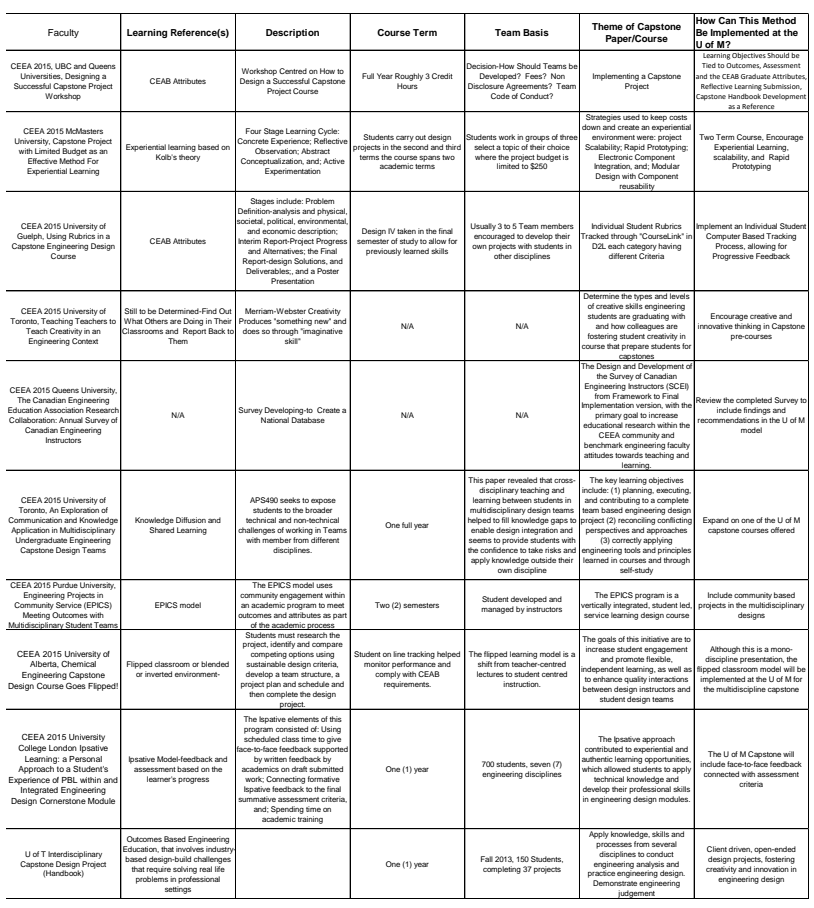

\section{APPENDIX 3: FOCUS GROUP DEVELOPMENT SCHEDULE}




\begin{tabular}{|c|c|c|c|c|}
\hline $\begin{array}{l}\text { Appendix } 3 \\
\text { Focus Group }\end{array}$ & & & & \\
\hline Date & $\begin{array}{l}\text { Internal/External } \\
\text { Focus Group }\end{array}$ & Participants & Decision Making Criteria & Outcomes \\
\hline April 22, 2015 & Internal & $\begin{array}{c}\text { Engineering } \\
\text { Discipline } \\
\text { Representatives }\end{array}$ & Agenda Presentation/Discussion/Consensus & $\begin{array}{l}\text { Disicipline Group Agreed to } \\
\text { Participate }\end{array}$ \\
\hline November 12, 2015 & Internal & $\begin{array}{c}\text { Engineering } \\
\text { Discipline } \\
\text { Representatives } \\
\end{array}$ & Agenda Presentation/Discussion/Consensus & Refined Participation Tasks \\
\hline April 14, 2016 & Internal & $\begin{array}{c}\text { Engineering } \\
\text { Discipline } \\
\text { Representatives }\end{array}$ & Agenda Presentation/Discussion/Consensus & $\begin{array}{c}\text { Agreed to Charrette Learning } \\
\text { Method and BOAM Presentation }\end{array}$ \\
\hline February 10, 2016 & External & $\begin{array}{c}\text { Architect, } \\
\text { Developer, } \\
\text { Builder, Co-op } \\
\text { Representative, }\end{array}$ & Agenda Presentation/Discussion/Consensus & $\begin{array}{c}\text { Agreed to Participate/Expanded } \\
\text { the Team/Condo Project Selected } \\
\text { as Example/All Meetings to be } \\
\text { held at Architects office }\end{array}$ \\
\hline February 24, 2016 & External & $\begin{array}{l}\text { Architect, } \\
\text { Developer, } \\
\text { Builder, Co-op } \\
\text { Representative, }\end{array}$ & Agenda Presentation/Discussion/Consensus & $\begin{array}{l}\text { Staged Performance Criteria } \\
\text { Established/IIvolvement Agreed }\end{array}$ \\
\hline March 23, 2015 & External & $\begin{array}{c}\text { Architect, } \\
\text { Developer, } \\
\text { Builder, Co-op } \\
\text { Representative, } \\
\text { Structural }\end{array}$ & Agenda Presentation/Discussion/Consensus & $\begin{array}{l}\text { Refined InvolvementTasks/Agreed } \\
\text { to Advertising }\end{array}$ \\
\hline April 13, 2016 & External & $\begin{array}{c}\text { Architect, } \\
\text { Developer, } \\
\text { Builder, Co-op } \\
\text { Representative, } \\
\text { Sstructural }\end{array}$ & Agenda Presentation/Discussion/Consensus & $\begin{array}{l}\text { Refined InvolvementTasks/Agreed } \\
\text { to Advertising }\end{array}$ \\
\hline
\end{tabular}

\section{APPENDIX 4: 62M MULTIFAMILY CONDOMINIUM COMPLEX}

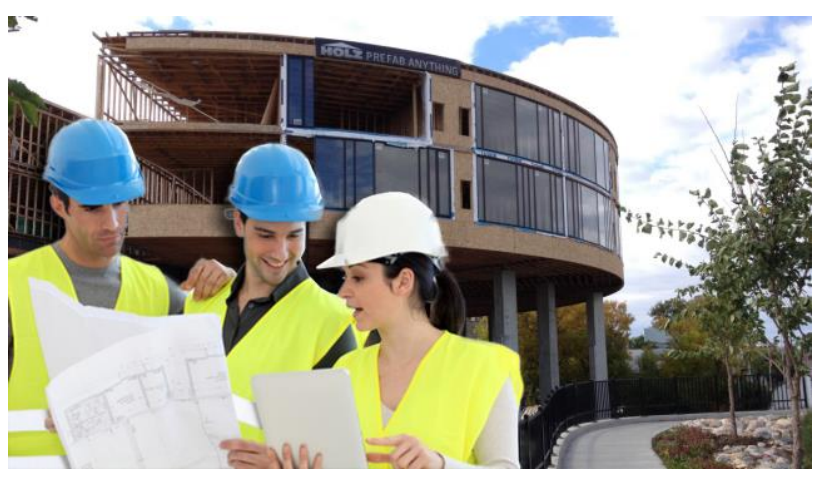

ENG-4010 Interdisciplinary Capstone Engineering Design -

Winter 2017

This course gives students an opportunity to apply the skills learned in engineering to a real world innovative design project, and experience working with an External Team including an architect, developer, general contractor, sub-consultants and the Jurisdictions Having Authority. The Internal Engineering Team will include students from Mechanical, Electrical and Computer, Biosystems and Civil Engineering disciplines. The course will focus on the real life integrated design process using a real project. The Internal Team will investigate all engineering aspects of the $62 \mathrm{M}$ Condominium project located at the south Disraeli Freeway (Image shown above). The Internal Team will develop engineering design questions. These questions will be reviewed evaluated by the External. To give a realistic perspective, a design scope change will be introduced at a later stage to allow for design innovation and creativity. The External Team and the Internal Team will work through the various aspects of the design from problem definition, conceptual design, detailed design. Lectures will be topical seminars given by the instructors, practicing engineers, and other relevant experts. Students will prepare written, oral design reports, as well as drawings on solutions. 